\title{
Growth optimization and applicability of thick on-axis SiC layers using sublimation epitaxy in vacuum
}

Valdas Jokubavicius, Jianwu Sun, Xinyu Liu, Gholamreza Yazdi, Ivan Gueorguiev Ivanov,

Rositsa Yakimova and Mikael Syväjärvi

\section{Linköping University Post Print}

\section{Tweet}

N.B.: When citing this work, cite the original article.

Original Publication:

Valdas Jokubavicius, Jianwu Sun, Xinyu Liu, Gholamreza Yazdi, Ivan Gueorguiev Ivanov, Rositsa Yakimova and Mikael Syväjärvi, Growth optimization and applicability of thick onaxis SiC layers using sublimation epitaxy in vacuum, 2016, Journal of Crystal Growth, (448), , 51-57.

http://dx.doi.org/10.1016/j.jcrysgro.2016.05.017

Copyright: Elsevier

http://www.elsevier.com/

Postprint available at: Linköping University Electronic Press

http://urn.kb.se/resolve?urn=urn:nbn:se:liu:diva-128610

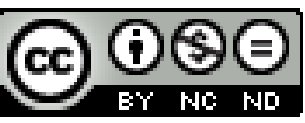





\title{
Growth optimization and applicability of thick on-axis SiC layers using sublimation epitaxy in vacuum
}

\author{
Valdas Jokubavicius $^{\star, 1}$, Jianwu Sun ${ }^{1}$, Xinyu Liu ${ }^{1}$, Gholamreza Yazdi ${ }^{1}$, \\ Ivan. G. Ivanov ${ }^{1}$, Rositsa Yakimova ${ }^{1}$ and Mikael Syväjärvi ${ }^{1}$ \\ ${ }^{1}$ Department of Physics, Chemistry and Biology, Linköping University, 58183 Linköping, Sweden \\ *Corresponding author: valjo@ifm.liu.se
}

\begin{abstract}
:
We demonstrate growth of thick SiC layers (100-200 $\mu \mathrm{m})$ on nominally on-axis hexagonal substrates using sublimation epitaxy in vacuum $\left(10^{-5} \mathrm{mbar}\right)$ at temperatures varying from 1700 to $1975^{\circ} \mathrm{C}$ with growth rates up to $270 \mu \mathrm{m} / \mathrm{h}$ and $70 \mu \mathrm{m} / \mathrm{h}$ for $6 \mathrm{H}$ - and $4 \mathrm{H}-\mathrm{SiC}$, respectively. The stability of hexagonal polytypes are related to process growth parameters and temperature profile which can be engineered using different thermal insulation materials and adjustment of the induction coil position with respect to the graphite crucible. We show that there exists a range of growth rates for which single-hexagonal polytype free of foreign polytype inclusions can be maintained. Further on, foreign polytypes like 3C-SiC can be stabilized by moving out of the process window. The applicability of on-axis growth is demonstrated by growing a $200 \mu \mathrm{m}$ thick homoepitaxial $6 \mathrm{H}$-SiC layer co-doped with nitrogen and boron in a range of $10^{18} \mathrm{~cm}^{-3}$ at a growth rate of about $270 \mu \mathrm{m} / \mathrm{h}$. Such layers are of interest as a near UV to visible light converters in a monolithic white light emitting diode concept, where subsequent nitride-stack growth benefits from the on-axis orientation of the SiC layer.
\end{abstract}

Keywords: A1. Mass transfer; A1. Substrates; A2. Single crystal growth; B2. Semiconducting materials; 


\section{Introduction}

The use of nominally on-axis instead of off-oriented substrates for homoepitaxial growth of hexagonal $(6 \mathrm{H}$ or $4 \mathrm{H}) \mathrm{SiC}$ polytypes has several advantages. On the production side, it would allow lower material losses during on-axis substrate cutting from $\mathrm{SiC}$ boules grown on nominally on-axis seeds, compared to off-axis cutting. From a point of view of device applications, on-axis epitaxial growth would significantly reduce the density of basal plane dislocations which affect negatively the performance of bipolar devices. [1,2] In addition, controlled growth of 3C-SiC on nominally on-axis hexagonal substrates may be applied to create 3C-SiC/4H-SiC or 3C-SiC/6H-SiC heterostructures which are attractive for high electron mobility transistors.[3] Further on, the development of a novel monolithic white light emitting diode (LED) concept may critically depend on the availability of homoepitaxial on-axis growth. In this LED concept a nitride-based stack is grown directly on donor and acceptor co-doped SiC epitaxial layers which must have on-axis orientation. [4,5] The near UV light emitted from the nitride-based stack is absorbed by the co-doped $\mathrm{SiC}$ layer and re-emitted as visible light via the donor-acceptor-pair recombination in the SiC layer (termed fluorescent $\mathrm{SiC})$. Thick layers $(>100 \mu \mathrm{m})$ are needed in order to have an efficient light conversion for general lighting purpose. To date, the homoepitaxial growth of fluorescent SiC was forced to apply low-off-axis (1-2 deg.) substrates in order to maintain the SiC substrate polytype via step flow growth mechanism. However, the quality of nitride layers (AlN and, subsequently, GaN or AlGaN) is greatly deteriorated by the offorientation of the $\mathrm{SiC}$ substrate. The nitride surface becomes rougher with larger substrate off-orientation and the nitride layers show high density of defects. [6] Therefore, the development of homoepitaxial growth on on-axis SiC has crucial significance for highquality nitride epitaxial growth and further successful development of such LED concept. 
However, homoepitaxial growth of SiC on nominally on-axis substrates still remains challenging due to formation of a mixture of cubic and hexagonal polytypes. In comparison with off-oriented substrates, the on-axis substrates do not possess high enough density of surface steps which would allow efficient step-flow growth when the polytype in the epilayer replicates the polytype of the substrate. Instead, the growth using nominally on-axis surfaces is challenged by spontaneous two dimensional nucleation of 3C-SiC islands. [7] A growth of 3C-SiC-free homoepitaxial layers on nominally on-axis 4H- and 6H-SiC substrates was demonstrated by several groups using Chemical Vapor Deposition (CVD) technique with different chemistries. $[1,8,9]$ In the sublimation based processes, similar to the well-established growth of hexagonal bulk SiC using the Physical Vapor Transport (PVT) technique, which allows higher growth rate than CVD, the formation of 3C-SiC is substantially suppressed by the use of high growth temperatures (typically higher than $2200^{\circ} \mathrm{C}$ ) and a background inert gas pressure. This enables control of the concentration of adsorbed atoms on the step terrace, thus avoiding 2D nucleation of 3CSiC. $[10,11]$ In contrast, the growth at temperatures below $2000^{\circ} \mathrm{C}$ favors the formation of 3C-SiC. Nevertheless, it has been demonstrated that the growth of homoepitaxial layers on off-oriented substrates at temperatures below $2000{ }^{\circ} \mathrm{C}$ degrees can be obtained using sublimation epitaxial growth. [12] This technique is essentially a modified PVT with a close space geometry and a source material in the form of a polycrystalline plate instead of sintered powder. A homoepitaxial growth with a growth rate up to $2 \mathrm{~mm} / \mathrm{h}$, which still allowed to maintain high crystalline quality, was demonstrated on off-oriented substrates using this technique. In contrast, the homoepitaxial growth on nominally on-axis $6 \mathrm{H}-\mathrm{SiC}$ substrates is difficult due to formation of 3C-SiC inclusions. [13] To date, controlled onaxis growth using sublimation epitaxy still remains a challenge and the role of all growth 
parameters is not well understood, in particular when thick layers and high growth rates are aimed.

In this paper we demonstrate that thick $(>100 \mu \mathrm{m})$ homoepitaxial SiC layers can be grown on nominally on-axis hexagonal $\mathrm{SiC}$ substrates at high growth rates using sublimation epitaxy by tailoring the temperature profiles. We clarify the importance of the properties of the insulation material on the temperature profile and the sensitivity of the process window for homoepitaxial growth limited in a growth-temperature range of 1700 to $1975^{\circ} \mathrm{C}$. We discuss also the interplay between the growth rate and $\mathrm{Si} / \mathrm{C}$ ratio and its importance for maintaining the hexagonal polytype, or for obtaining intentionally fully converted cubic SiC layer. As further demonstration of the control of the homoepitaxial growth even when high doping with impurities in the range of $10^{18} \mathrm{~cm}^{-3}$ is performed, we have grown thick fluorescent SiC layers on nominally on axis substrates.

\section{Materials and methods}

The growth setup consisted of an inductively heated high density graphite crucible surrounded by porous graphite acting as insulating material. [12] The operating frequency of the generator was $46 \mathrm{kHz}$. An axial temperature gradient is the driving force for vapor species transport from the polycrystalline SiC plate to the substrate. The source and the substrate, separated by a graphite spacer with $1 \mathrm{~mm}$ thickness, were placed inside the growth crucible. The spacer had a circular opening (7 $\mathrm{mm}$ in diameter) which created a growth cavity between the source and the substrate. In order to prevent backside sublimation of the substrate, a graphite plate was placed on top of it. In addition, a tantalum carbide plate was placed at the bottom of the crucible in order to obtain more uniform heating of the source. The temperature profile in this type of growth arrangement is given by the geometries of the crucible and the insulation, their thermal properties, and 
the position of the induction coil with respect to the crucible position. We explored two growth setups with identical geometrical design of crucible and insulation, but different thermal properties of the insulation material. The SiC layers were grown in vacuum $\left(10^{-5}\right.$ mbar) on Si-face of nominally on-axis $6 \mathrm{H}$ - and $4 \mathrm{H}-\mathrm{SiC}(0001)$ substrates cut in $10 \times 10$ $\mathrm{mm}^{2}$ samples which were chemically cleaned with acetone and ethanol followed by $\mathrm{H}_{2} \mathrm{O}: \mathrm{NH}_{3}: \mathrm{H}_{2} \mathrm{O}_{2}$ (5:1:1) and $\mathrm{H}_{2} \mathrm{O}: \mathrm{HCl}: \mathrm{H}_{2} \mathrm{O}_{2}$ (6:1:1). The growth temperature was varied from 1700 to $1975^{\circ} \mathrm{C}$. The temperature was measured on the top of the crucible using digital infrared pyrometer. Temperature ramp-up to the growth temperature of $20 \mathrm{~K} / \mathrm{min}$ was used in all experiments. The temperature and $\mathrm{Si} / \mathrm{C}$ ratio distributions in the growth setup were simulated using Virtual Reactor (SRT) software with the SiC-PVT package. [14]

The samples were analyzed by optical microscope with Nomarski interference contrast, atomic force microscope and scanning electron microscope. In addition, polytype identification was done using low temperature photoluminescence (LTPL) at temperature of $2 \mathrm{~K}$. The LTPL spectra were measured using the $351 \mathrm{~nm}$ line of an Ar-ion laser for excitation and collected by a monochromator fitted with a 1200 grooves/mm grating in combination with a charge-coupled device (CCD) camera. Room temperature photoluminescence was measured using a USB2000+ spectrometer under the excitation of two low power light emitting diodes with a wavelength of $375 \mathrm{~nm}$.

\section{Results and discussion}

The temperature difference between the source and the substrate can be modified by changing the induction coil position with respect to the crucible, or by using thermal insulations with different properties. We used both approaches to modify the temperature 
profile. We applied three different induction coil positions and two different insulation setups, the latter were composed of three parts: upper, central and lower (Fig. 1).

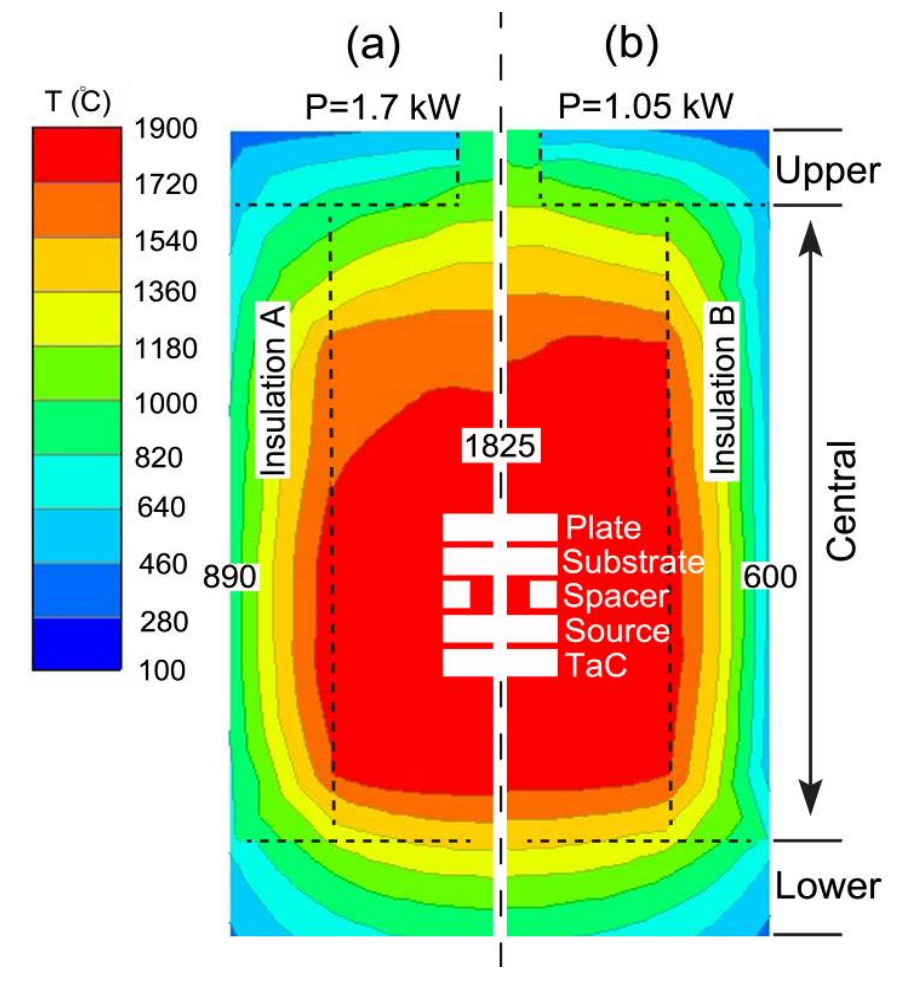

Figure 1. Cross-section of the simulated temperature profiles of growth setups with different insulation materials in the central part: (a) insulation A (higher radial thermal conductivity), (b) insulation B (lower radial thermal conductivity). The temperature profiles are axially symmetric, hence only half of the corresponding cross-section is shown to the left (right) for insulation A (B), respectively. The graphite crucible, coil position, upper and lower insulation parts are the same in both cases.

The upper and lower parts, which cover the top and the bottom of the crucible, were made of the same insulation material in both setups. The central parts were fabricated using two different anisotropic insulation materials denoted as insulation A and B. The insulation A had almost three times higher radial and almost two times lower axial thermal conductivity. This results in a difference in the heat dissipation in the two setups. As a 
consequence, in order to reach the same growth temperature, higher induction heating power has to be applied using insulation A compared to insulation B. In our case, $1.7 \mathrm{~kW}$ induction heating power is used with insulation $\mathrm{A}$, and $1.05 \mathrm{~kW}$ with insulation $\mathrm{B}$ in order to achieve the same growth temperature of $1825^{\circ} \mathrm{C}$ (Fig .1).

The effect of the two different insulation materials is studied using a growth series performed in the temperature range of 1700 to $1975^{\circ} \mathrm{C}$ and three different coil positions with respect to the crucible position. The coil positions are denoted as "Low", "Mid" and "High". In the "Low" position the center of the coil is aligned with the center of the crucible, while the "Mid” and the "High" positions corresponds to the coil being moved up by $25 \mathrm{~mm}$ and $35 \mathrm{~mm}$, respectively. Simulations show that the temperature difference between the source and the substrate using insulation $\mathrm{A}$ is about $\sim 40{ }^{\circ} \mathrm{C}$ at "Low" , $\sim 24{ }^{\circ} \mathrm{C}$ at "Mid" and $\sim 18{ }^{\circ} \mathrm{C}$ at "High" position. In the case of insulation B the corresponding temperature differences are substantially lower, $\sim 24{ }^{\circ} \mathrm{C}$ at "Low", $\sim 14{ }^{\circ} \mathrm{C}$ at "Mid" and $\sim 8^{\circ} \mathrm{C}$ at "High" position. Based on simulations, the radial temperature difference between the center and the edge of the layer varies only up to 0.2 degree at different coil positons in respective setups.

Figure 2 presents an overview of the growth rates as functions of temperature for the two different setups and at different coils positions. The maximum growth rates for which homoepitaxial growth of hexagonal $\mathrm{SiC}$ without cubic inclusions was observed are also denoted in the figure. Using insulation A resulted in homoepitaxial growth of $6 \mathrm{H}-\mathrm{SiC}$ only at the "High" coil position with a maximum growth rate of $125 \mu \mathrm{m} / \mathrm{h}$, whereas layers grown using "Mid" and "Low" coil positions contained 3C-SiC inclusions for all growth temperatures used (Fig. 2 (a, b, c)). In contrast, using insulation B it was possible to obtain homoepitaxial layers of $6 \mathrm{H}-\mathrm{SiC}$ for all three coil positions, but at different maximum 
growth rates, as denoted in Fig. 2 (d, e, f). For instance, the maximum growth rates before 3C-SiC inclusions started to appear in the homoepitaxial growth of $6 \mathrm{H}-\mathrm{SiC}$ were 270, 230 and $90 \mu \mathrm{m} / \mathrm{h}$ at the "High”, "Mid” and "Low” positions, respectively. The polytype stability of $4 \mathrm{H}-\mathrm{SiC}$ was also explored, but homoepitaxial layers of $4 \mathrm{H}-\mathrm{SiC}$ were only obtained at the "High" position using insulation B at a maximum growth rate of $70 \mu \mathrm{m} / \mathrm{h}$.

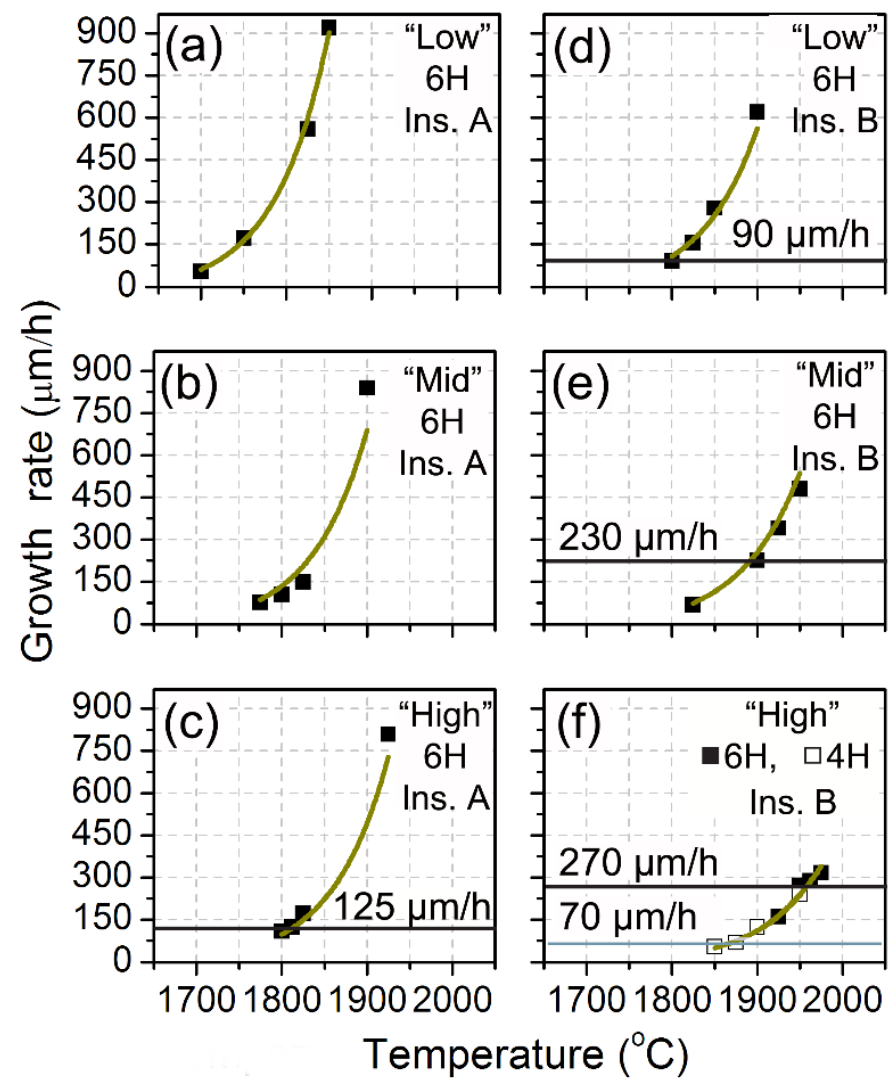

Figure 2. Growth rate vs temperature for both insulations at: (a,d)”Low”, (b, e)”Mid” and (c, f) "High” coil positions. Horizontal solid lines indicate highest homoepitaxial growth rates of $6 \mathrm{H}-\mathrm{SiC}$ (black) and 4H-SiC (grey). Parts (a) and (b) have no horizontal lines since all layers contained 3C-SiC inclusions. The curved lines represent simulated growth rates.

The overview given in Fig. 2 indicates that there is a particular operational window for homoepitaxial on-axis growth in the growth rate-temperature range explored. We 
simulated $\mathrm{Si} / \mathrm{C}$ ratios of the sublimed vapor species close to the substrate surface. The results are summarized in Fig. 3.

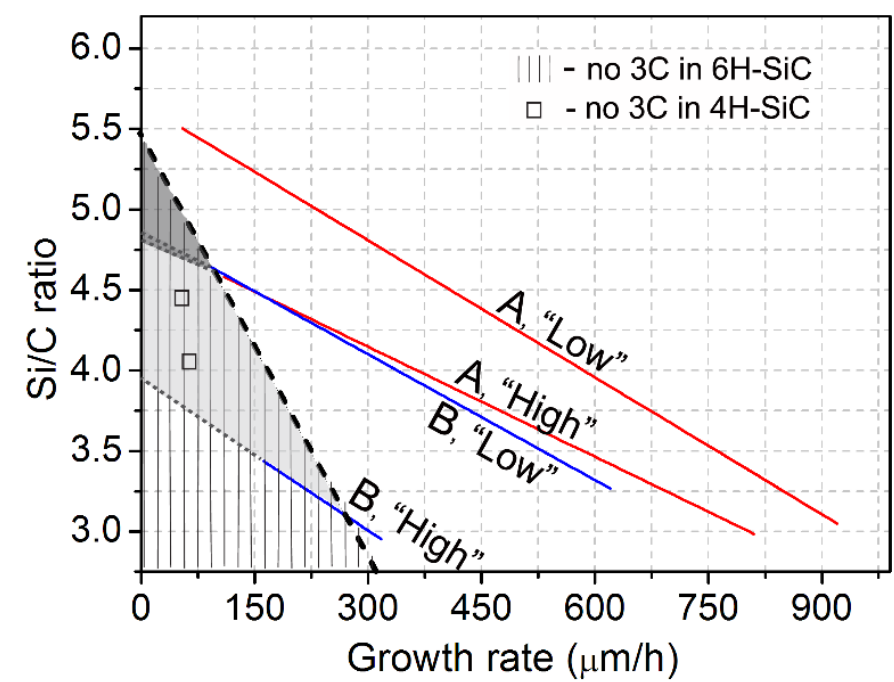

Figure 3. Operational window for homoepitaxial growth based on experimental data and simulated $\mathrm{Si} / \mathrm{C}$ ratios versus growth rate, as discussed in text.

The red lines in Fig. 3 correspond to insulation A and the blue ones - to insulation B. These lines represent linearly fitted Si/C ratios for the "Low" and "High" coil positions. The dashed line represents a linear fit of the experimental points at which homoepitaxial growth of $6 \mathrm{H}-\mathrm{SiC}$ at the highest growth rates using different insulation materials and coil positions was obtained. The hatched triangular area under the dashed line indicates the process window at which a homoepitaxial $6 \mathrm{H}-\mathrm{SiC}$ growth is maintained. If the red and blue lines are extended across this hatched triangle, the intersecting grey areas (shaded) represent the homoepitaxial $6 \mathrm{H}-\mathrm{SiC}$ growth windows for each insulation at respective coil positions. In addition, we plotted simulated Si/C data points which indicate homoepitaxial 4H-SiC growth using insulation B and "High" coil position. Since we only have two 
experimental points in this case, the operational window for $4 \mathrm{H}-\mathrm{SiC}$ seems to be substantially narrower and shifted to a lower growth rate region compared to 6H-SiC. As already noticed above, the use of insulation B leads to a lower temperature gradient between the source and the substrate, which results in a lower growth rate and lower supersaturation at a given growth temperature and coil position, compared to insulation A. These differences can be used to control the stability of the hexagonal polytype or, alternatively, to enhance the formation of 3C-SiC. In general, it is considered that the homogeneous formation of 3C-SiC on hexagonal polytypes is more stable at lower temperatures, higher supersaturation or more Si rich vapor conditions. $[10,11]$ This notion is in agreement with our experimental results. For example, epitaxial layers grown on $6 \mathrm{H}-$ $\mathrm{SiC}$ at the same temperature and coil position, but different insulation setups exhibit significantly larger surface coverage with 3C-SiC using insulation A which induces larger temperature gradient leading to higher growth rate and supersaturation compared to insulation B. The results obtained with the two different insulations are summarized in Table 1.

Table 1.Experimental data on 3C-SiC surface coverage comparing the results using the two insulations $\mathrm{A}$ and $\mathrm{B}$ for three growth temperatures.

\begin{tabular}{|l|l|l|l|l|l|l|}
\hline Growth temperature $\left({ }^{\circ} \mathrm{C}\right)$ & 1850 & 1900 & \multicolumn{2}{l|}{1925} \\
\hline Insulation & A & B & A & B & A & B \\
\hline Growth rate $(\mu \mathrm{m} / \mathrm{h})$ & 900 & 280 & 840 & 230 & 790 & 160 \\
\hline Layer thickness $(\mu \mathrm{m})$ & 200 & 140 & 270 & 200 & 240 & 140 \\
\hline Coil position & Low & Mid & \multicolumn{3}{l|}{ High } \\
\hline 3C-SiC coverage $(\%)$ & 95 & 5 & 80 & 0 & 50 & 0 \\
\hline
\end{tabular}

We compared also epitaxial layers grown with the two insulations at the same growth rate. In order to obtain similar growth rates using both insulation setups at a given coil position, 
a lower temperature has to be applied for insulation A. Due to the incongruent sublimation of $\mathrm{SiC}$ a lower growth temperature leads to more Si-rich growth environment. Two SiC layers (thickness about $150 \mu \mathrm{m}$ ) were grown at a similar growth rate of about $160 \mu \mathrm{m} / \mathrm{h}$ on $6 \mathrm{H}-\mathrm{SiC}$ substrate using the "Low” coil position, but different insulation materials. We used growth temperature of $1825{ }^{\circ} \mathrm{C}$ with insulation $\mathrm{B}$ and $1750{ }^{\circ} \mathrm{C}$ with insulation $\mathrm{A}$. As seen from the cross-sectional view of the resulting samples in Fig.4, there is an obvious difference in 3C-SiC yield at similar growth rates. The layer grown using insulation B (Fig. 4a) contains only a few 3C-SiC growth centers, while the amount of 3C-SiC in the layer grown using insulation $\mathrm{A}$ is substantially higher with a complete conversion at the top of the whole layer from hexagonal to cubic SiC polytype. (Fig.4b).
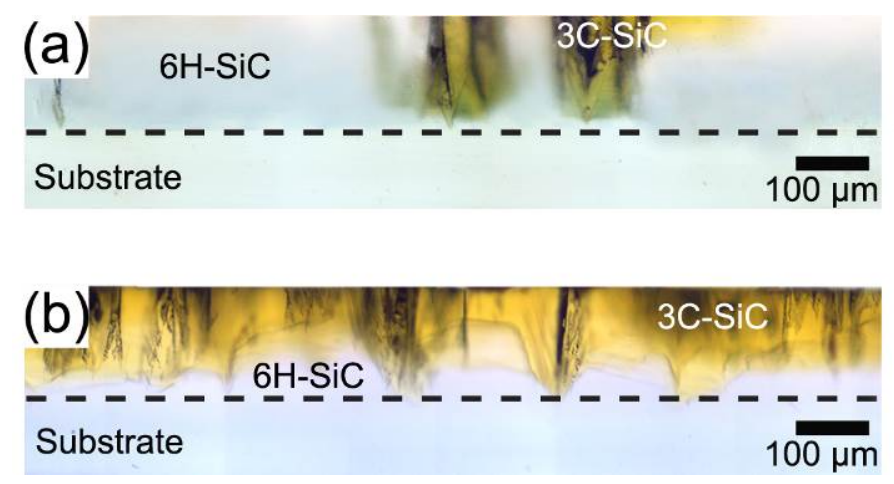

Figure 4. Cross-sectional view of $6 \mathrm{H}-\mathrm{SiC}$ layers grown outside the homoepitaxial growth process window using insulation: a) B, b) A

In case of growth of 4H-SiC, we used insulation B and "High" coil position. As discussed in connection to Fig. 2f, the layer grown at $70 \mu \mathrm{m} / \mathrm{h}$ maintained the substrate polytype, but higher growth rates resulted in an increase of 3C-SiC inclusions. For example, 4H-SiC layers grown at 125 and $240 \mu \mathrm{m} / \mathrm{h}$ contained 3C-SiC inclusions which accounted for the surface coverage of $15 \%$ and $45 \%$, respectively. 
It was previously suggested by Vasiliauskas et al.[13] that a model, originally developed for CVD growth, can be employed to explain the formation of 3C-SiC on step terraces using sublimation epitaxy. $[7,13]$ This model analyzes the competition between 2D nucleation of 3C-SiC and "step-flow" growth modes. It was demonstrated that the 3C-SiC polytype stabilizes after a certain supersaturation threshold of adatoms on step terraces is exceeded. Below this threshold there is $6 \mathrm{H}-\mathrm{SiC}$ homoepitaxial growth which can commence as a spiral growth or, under certain conditions, in the 2D growth mode. These experiments were performed at a fixed coil position and the supersaturation value was increased by increasing the growth rate/temperature. It was shown that the homoepitaxial growth of $6 \mathrm{H}-\mathrm{SiC}$ can be maintained up to about $1700^{\circ} \mathrm{C}$ which led to a growth rate of less than $50 \mu \mathrm{m} / \mathrm{h}$. Our results are in excellent agreement with the 3C-SiC formation model suggested by Vasiliauskas et al. [13] However, we demonstrate in addition that the process window for $6 \mathrm{H}-\mathrm{SiC}$ stability can be significantly expanded by engineering the temperature profile by means of different insulations and induction coil positions.

Also, the occurrence of 3C-SiC can be explained by theoretical model which relates $\mathrm{Si}$ and C atoms activities with stability of different SiC polytypes. [15] The formation of 3C-SiC is preferable at higher Si activity which increases by reducing growth temperature, pressure or increasing temperature gradient between the source and the substrate. In fact, our experimental results support this model very well since we observed higher stability of 3C-SiC at lower growth temperatures and higher temperature gradients.

The surface morphology of the layers grown at the highest homoepitaxial growth rates obtained within this study is illustrated in Fig. 5. The 6H-SiC layer contains large islands with stepped surface (Fig. 5 (a, c)). The $4 \mathrm{H}-\mathrm{SiC}$ surface is rougher with more growth centers (Fig. 5 (b, d)). Etching in molten $\mathrm{KOH}$ at $500^{\circ} \mathrm{C}$ for 1 min revealed that in $6 \mathrm{H}-\mathrm{SiC}$ 
the dislocations are spread uniformly over the surface (Fig. 5 (e)), while in $4 \mathrm{H}-\mathrm{SiC}$ they mostly agglomerate into dislocation clusters, some of which coincide with spiral centers (Fig. 5 (f)). A rougher surface structure with a presence of dislocation clusters could possibly be one of the reasons causing lower stability of $4 \mathrm{H}-\mathrm{SiC}$ compared to $6 \mathrm{H}-\mathrm{SiC}$. It has been demonstrated that high density of dislocations could cause formation of 3C-SiC inclusions. [16]
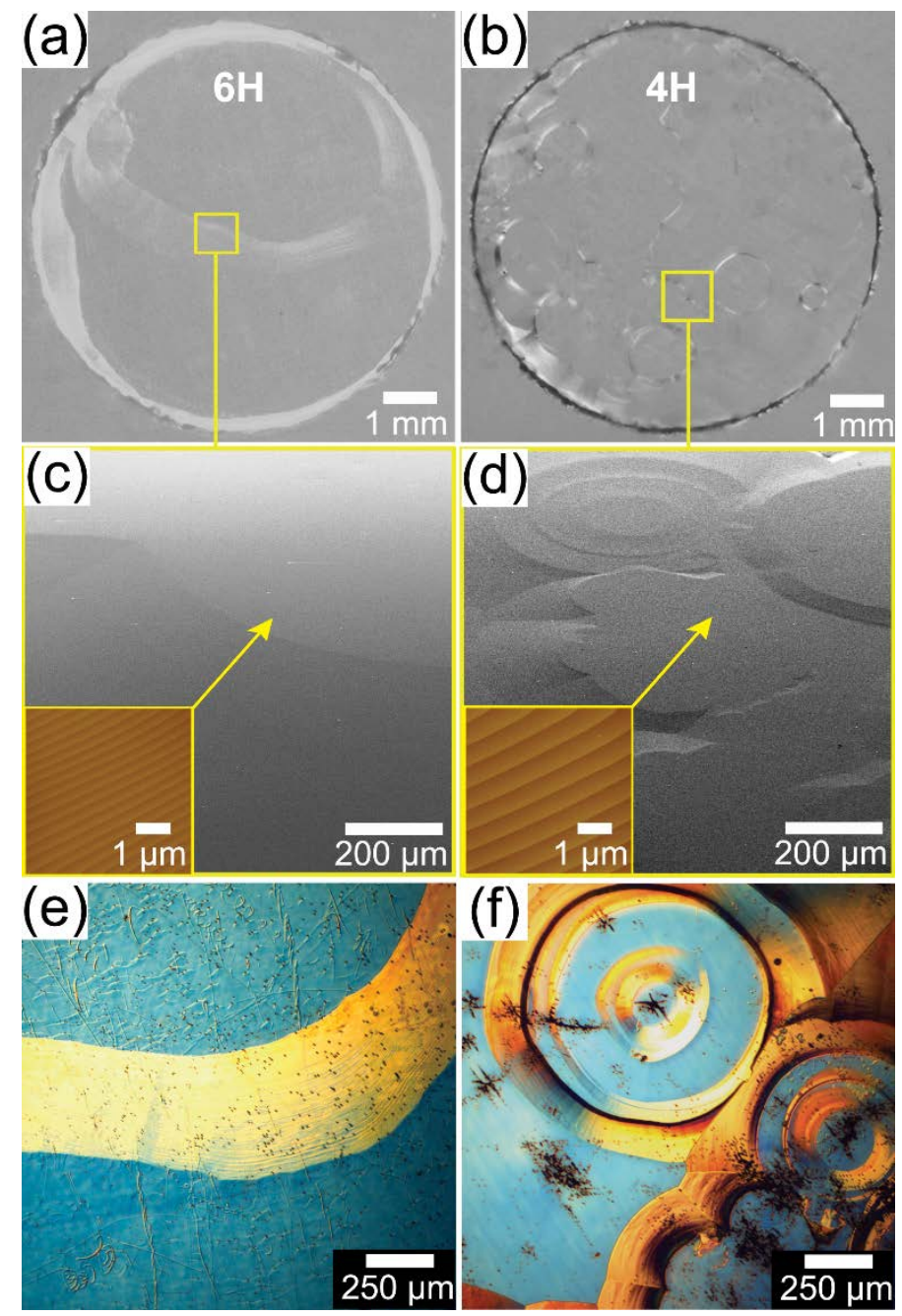

Figure 5. Optical micrographs of: (a) $6 \mathrm{H}-\mathrm{SiC}$, thickness $205 \mu \mathrm{m}$, growth rate $270 \mu \mathrm{m} / \mathrm{h}$, (b) 4H-SiC, thickness $130 \mu \mathrm{m}$, growth rate $70 \mu \mathrm{m} / \mathrm{h}$. The enlarged areas in (c) for $6 \mathrm{H}$ - and (d) 
for $4 \mathrm{H}-\mathrm{SiC}$ are taken using SEM. Insets in (c-d) are AFM images of the areas pointed by arrows. (e) and (f) $\mathrm{KOH}$ etched surfaces of $6 \mathrm{H}-$ and $4 \mathrm{H}-\mathrm{SiC}$ respectively.

In order to confirm the quality of the homoepitaxial layers, we performed low temperature photoluminescence measurement at $2 \mathrm{~K}$. The $6 \mathrm{H}$ - and $4 \mathrm{H}-\mathrm{SiC}$ layers exhibit the typical near band edge emission lines for the respective polytype (Fig. 6a, b).
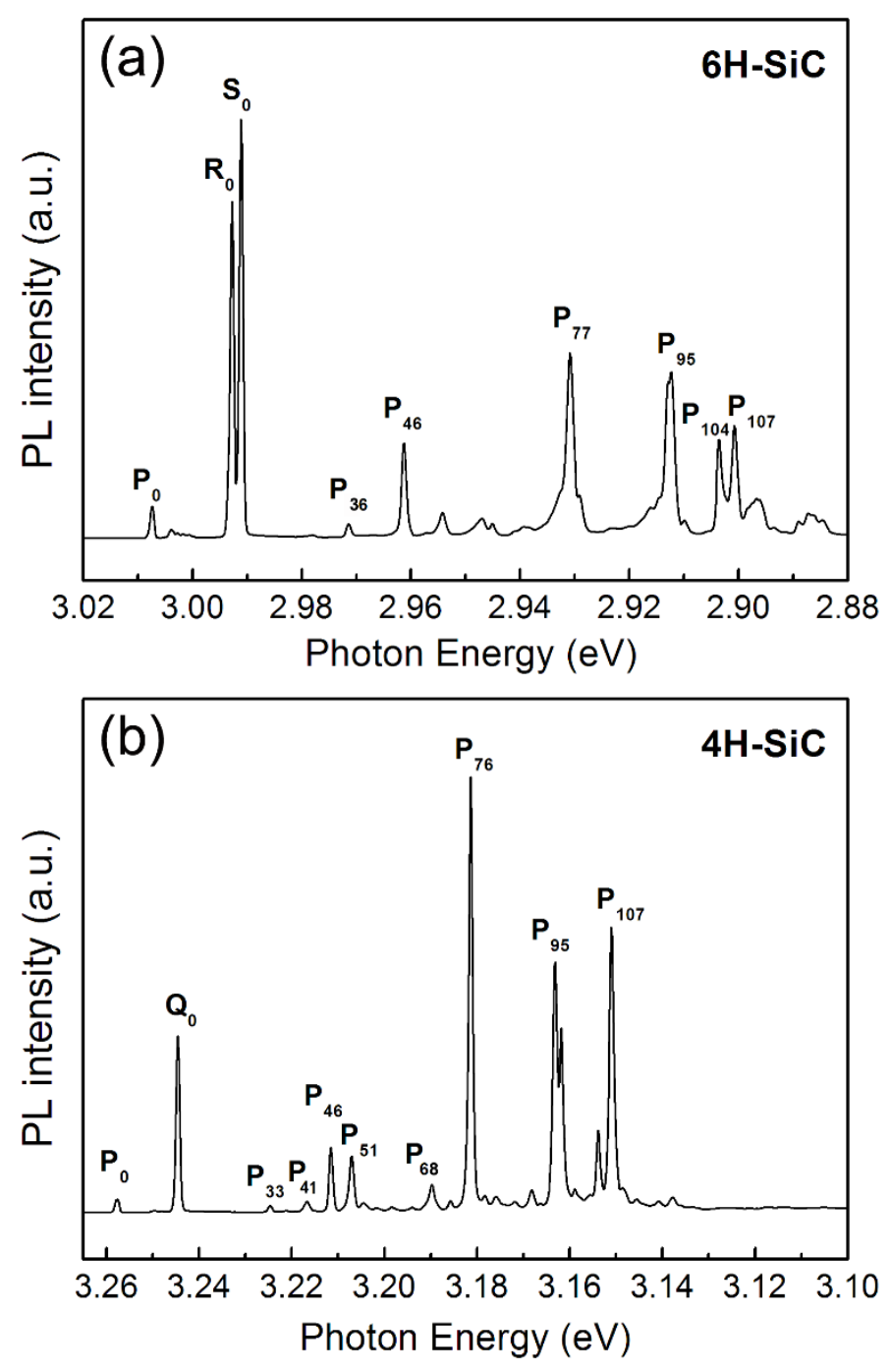

Figure 6. LTPL spectra of: a) $6 \mathrm{H}-\mathrm{SiC}$, b) $4 \mathrm{H}-\mathrm{SiC}$ 
$P_{0}, R_{0}, S_{0}$ in Fig 6a and $P_{0}, Q_{0}$ in Fig 6b denote the zero-phonon lines of nitrogen-bound excitons in $6 \mathrm{H}-\mathrm{SiC}$ and $4 \mathrm{H}-\mathrm{SiC}$, respectively. In both cases, $P_{0}$ denotes the zero-phonon line of the exciton bound to nitrogen donor at the hexagonal lattice site while $R_{0}$, $S_{0}$ (in $6 \mathrm{H}$ $\mathrm{SiC}$ ) and $\mathrm{Q}_{0}$ (in $4 \mathrm{H}-\mathrm{SiC}$ ) lines are attributed to the zero-phonon lines of nitrogen donor bound excitons at the cubic lattice sites (two in $6 \mathrm{H}$ - and one in $4 \mathrm{H}-\mathrm{SiC}$ ). Some of the strongest phonon replicas due to exciton recombination of the nitrogen-bound excitons at hexagonal sites $\left(P_{m}\right.$ lines, where $m$ denotes the phonon energy in $\left.m e V\right)$ are also denoted in the figure. We notice that the spectral regions displayed in Fig. 6 are parts of larger spectra recorded in the range $3700-6000 \AA$ (not shown), which covers essentially the near band gap emissions of all common SiC polytypes, but no emission from foreign polytypes was observed in neither of the spectra. Thus, the sharpness of the nitrogen-bound-exciton lines and the absence of spectral signatures of other polytypes confirms the high quality of the hexagonal layers.

Finally, as a demonstration for a practical implementation of the on-axis growth, we grew boron and nitrogen (donor and acceptor) co-doped 6H-SiC layer on a quarter of a 2 inch on-axis substrate acting as fluorescent $\mathrm{SiC}$ in the white LED structure. [5] We used insulation B and "High” coil position to grow the layer with a thickness of 200 micrometers. The growth was performed at $1950{ }^{\circ} \mathrm{C}$ for $45 \mathrm{~min}$. The dopants were introduced from polycrystalline SiC plates doped with nitrogen and boron in the range of $10^{18} \mathrm{~cm}^{-3}$. The room-temperature photoluminescence was excited by two UV-emitting diodes. Under this excitation strong donor - acceptor pair (DAP) luminescence uniformly distributed over the whole sample was observed, as shown in Fig. 7. This also indicates that a uniform polytype without macroscopic defects, or any visible 3C-SiC or other polytype inclusions was achieved using on-axis growth. 


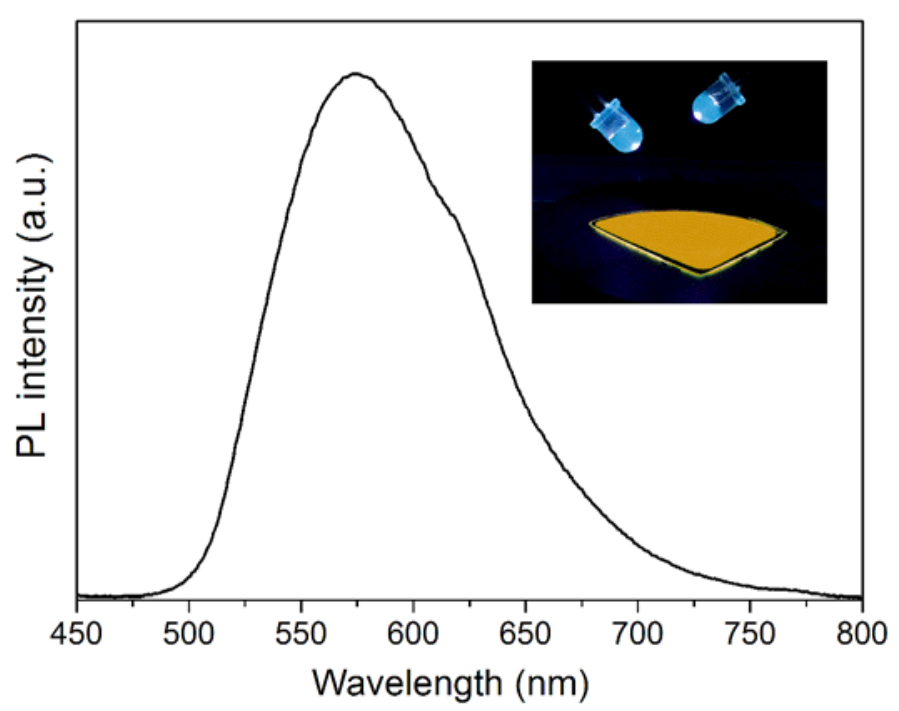

Figure 7. Room temperature photoluminescence of nitrogen and boron co-doped 6H-SiC.

The inserted photograph illustrates the homogeneous distribution of the DAP luminescence over the sample.

The optimization of light conversion efficiency in fluorescent SiC needs additional studies. However, the implementation of the monolithic white LED concept $[4,5]$ could critically depend on the ability to grow fluorescent $\mathrm{SiC}$ on nominally on-axis substrates because the latter provides better template for the subsequent higher-quality nitride stack growth. Thus, the on-axis growth of fluorescent $\mathrm{SiC}$ could contribute to the overall improvement of the monolithic white LED performance.

\section{Conclusions}

We demonstrated that the engineering of the temperature profile using different insulation material and applying different induction coil positions with respect to the graphite crucible has a pronounced effect on the control of hexagonal or cubic polytype stability when using sublimation epitaxial growth in vacuum on nominally on-axis $6 \mathrm{H}$ - and $4 \mathrm{H}-\mathrm{SiC}$ (0001) substrates. The use of insulation materials with different thermal properties 
significantly changes the thermal profile inside the graphite crucible, especially, the temperature gradient between the source and the substrate. Consequently, different insulations can be used to control the operational window for epitaxial growth of hexagonal or cubic SiC polytype. As an example of such control, we grew $200 \mu \mathrm{m}$ thick nitrogen and boron co-doped 6H-SiC layer which can be used as a near UV to visible light converter in monolithic white LED structure.

\section{Acknowledgement}

This project is partly supported by Swedish Research Council (contracts 621-2014-5825, 621-2014-5461), Swedish Energy Agency, Swedish Governmental Agency for Innovation Systems (Vinnova) and by the Innovation Fund Denmark (LEDSiC project No. 410600018B).

\section{References}

[1] J. Hassan, J.P. Bergman, A. Henry, E. Janzén, On-axis homoepitaxial growth on Siface 4H-SiC substrates, J. Cryst. Growth. 310 (2008) 4424-4429.

[2] M. Skowronski, S. Ha, Degradation of hexagonal silicon-carbide-based bipolar devices, J. Appl. Phys. 99 (2006) 011101. doi:10.1063/1.2159578.

[3] V.M. Polyakov, F. Schwierz, Formation of two-dimensional electron gases in polytypic SiC heterostructures, J. Appl. Phys. $98 \quad$ (2005) 23709. doi:http://dx.doi.org/10.1063/1.1984070.

[4] Y. Ou, V. Jokubavicius, S. Kamiyama, C. Liu, R.W. Berg, M. Linnarsson, et al., Donor-acceptor-pair emission characterization in N-B doped fluorescent SiC, Opt. Mater. Express. 1 (2011) 1439. doi:10.1364/OME.1.001439.

[5] S. Kamiyama, M. Iwaya, T. Takeuchi, I. Akasaki, M. Syväjärvi, R. Yakimova, 
Fluorescent SiC and its application to white light-emitting diodes, J. Semicond. 32 (2011) 13004.

[6] M. Rudziński, E. Jezierska, J.L. Weyher, L. Macht, P.R. Hageman, J. Borysiuk, et al., Defect formation in GaN grown on vicinal 4H-SiC (0001) substrates, Phys. Status Solidi. 204 (2007) 4230-4240. doi:10.1002/pssa.200723324.

[7] T. Kimoto, H. Matsunami, Surface kinetics of adatoms in vapor phase epitaxial growth of SiC on 6H-SiC\{0001\} vicinal surfaces, J. Appl. Phys. 75 (1994) 850-859. doi:10.1063/1.356439.

[8] S. Nakamura, T. Kimoto, H. Matsunami, Homoepitaxy of 6H-SiC on nearly on-axis (0 000 1) faces by chemical vapor deposition Part I: Effect of C/Si ratio on wide-area homoepitaxy without 3C-SiC inclusions, J. Cryst. Growth. 256 (2003) 341-346. doi:http://dx.doi.org/10.1016/S0022-0248(03)01385-X.

[9] S. Leone, H. Pedersen, A. Henry, O. Kordina, E. Janzén, Thick homoepitaxial layers grown on on-axis Si-face $6 \mathrm{H}$ - and $4 \mathrm{H}-\mathrm{SiC}$ substrates with $\mathrm{HCl}$ addition, J. Cryst. Growth. 312 (2009) 24-32. doi:10.1016/j.jcrysgro.2009.10.011.

[10] Y.M. Tairov, V.F. Tsvetkov, Progress in controlling the growth of polytypic crystals, Prog. Cryst. Growth Charact. 7 (1983) 111-162. doi:http://dx.doi.org/10.1016/01463535(83)90031-X

[11] A. Fissel, Artificially layered heteropolytypic structures based on SiC polytypes: molecular beam epitaxy, characterization and properties, Phys. Rep. 379 (2003) 149_ 255. doi:10.1016/S0370-1573(02)00632-4.

[12] M. Syväjärvi, R. Yakimova, M. Tuominen, A. Kakanakova-Georgieva, M.F. MacMillan, A. Henry, et al., Growth of $6 \mathrm{H}$ and $4 \mathrm{H}-\mathrm{SiC}$ by sublimation epitaxy, J. Cryst. Growth. 197 (1999) 155-162. doi:http://dx.doi.org/10.1016/S0022- 
0248(98)00890-2.

[13] R. Vasiliauskas, M. Marinova, P. Hens, P. Wellmann, M. Syväjärvi, R. Yakimova, Nucleation Control of Cubic Silicon Carbide on 6H- Substrates, - Cryst. Growth Des. 12 (2012) 197. doi:10.1021/cg200929r.

[14] M.V. Bogdanov, A.O. Galyukov, S.Y. Karpov, A.V. Kulik, S.K. Kochuguev, D.K. Ofengeim, et al., Virtual reactor as a new tool for modeling and optimization of SiC bulk crystal growth, J. Cryst. Growth. 225 (2001) 307-311. doi:10.1016/S00220248(01)00879-X.

[15] K. Ariyawong, C. Chatillon, E. Blanquet, J.-M. Dedulle, D. Chaussende, A first step toward bridging silicon carbide crystal properties and physical chemistry of crystal growth, CrystEngComm. 18 (2016) 2119-2124. doi:10.1039/C5CE02480C.

[16] J.A. Powell, J.B. Petit, J.H. Edgar, I.G. Jenkins, L.G. Matus, J.W. Yang, et al., Controlled growth of 3C-SiC and 6H-SiC films on low-tilt-angle vicinal (0001) 6HSiC wafers, Appl. Phys. Lett. $59 \quad$ (1991) 333-335. doi:http://dx.doi.org/10.1063/1.105587. 